\title{
QUAL A PERCEPÇÃO DOS ESTUDANTES EM RELAÇÃO ÀS ATIVIDADES GAMIFICADAS? UM ESTUDO SOBRE MOTIVAÇÃO NO ENSINO SUPERIOR
}

\author{
Gabriela Troyano Bortoloto ${ }^{1}$ \\ https://orcid.org/0000-0002-3023-2609 \\ Vitor Mendes Stafusa ${ }^{2}$ \\ https://orcid.org/0000-0002-8513-6614
}

RESUMO: Este artigo objetivou estudar a relação existente entre a utilização de elementos de jogos e a motivação dos estudantes para participar de atividades acadêmicas que exijam uma postura ativa. Através de uma abordagem qualitativa, foi analisada uma universidade que reformou um evento acadêmico inserindo elementos de jogos (gamificação). Um dos resultados obtidos indica que grande parte dos alunos avaliaram positivamente a iniciativa, afirmando que houve um aumento em sua motivação. Também foi possível avaliar, neste caso, quais elementos de jogos estão mais relacionados com as motivações intrínseca e extrínseca. Além disso, foram apontados alguns problemas organizacionais que podem ter influenciado na motivação dos participantes durante o evento. Por fim, espera-se que este artigo possa levantar reflexões práticas quanto ao uso da gamificação em eventos acadêmicos.

PALAVRAS-CHAVE: motivação, metodologias ativas, gamificação, ensino superior.

\section{WHAT ARE THE STUDENTS 'PERCEPTION TOWARDS GAMIFIED ACTIVITIES? A STUDY ON MOTIVATION IN HIGHER EDUCATION}

ABSTRACT: This paper aimed to study the relationship between the use of game elements and students' motivation to participate in academic activities that require an active attitude. Through a qualitative approach, a university that reformed an academic event by inserting elements of games (gamification) was analyzed. One of the results indicates that most students positively evaluated the initiative, stating that

\footnotetext{
${ }^{1}$ Doutoranda em Administração.Universidade de São Paulo (USP). São Paulo, São Paulo, Brasiltroyano@ usp.br

${ }^{2}$ Mestrando em Arquitetura e Urbanismo. Universidade Estadual Paulista (UNESP), Bauru, São Paulo, Brasil.v.stafusa@unesp.br
} 
there was an increase in their motivation. It was also possible to assess, in this case, which elements of games are most related to intrinsic and extrinsic motivations. In addition, some organizational problems were pointed out that may have influenced the motivation of the participants during the event. Finally, it is hoped that this article may raise practical reflections regarding the use of gamification in academic events.

KEYWORDS: motivation, active methodologies, gamification, higher education.

\section{¿CUÁL ES LA PERCEPCIÓN DE LOS ESTUDIANTES EN RELACIÓN CON LAS ACTIVIDADES GAMIFICADAS? ESTUDIO SOBRE MOTIVACIÓN EN LA EDUCACIÓN SUPERIOR}

RESUMEN: Este artículo tuvo como objetivo estudiar la relación entre el uso de elementos del juego y la motivación de los estudiantes para participar en actividades académicas que requieren una actitud activa. A través de un enfoque cualitativo, se analizó una universidad que reformó un evento académico insertando elementos de juegos (gamificación). Uno de los resultados obtenidos indica que la mayoría de los estudiantes evaluó positivamente la iniciativa, manifestando que hubo un aumento en su motivación. También fue posible evaluar, en este caso, qué elementos de los juegos están más relacionados con motivaciones intrínsecas y extrínsecas. Además, se señalaron algunos problemas organizativos que pueden haber influido en la motivación de los participantes durante el evento. Finalmente, se espera que este artículo pueda suscitar reflexiones prácticas sobre el uso de la gamificación en eventos académicos.

PALABRAS CLAVE: motivación, metodologías activas, gamificación, educación superior.

\section{Introdução}

Visando dinamizar o processo de ensino-aprendizagem, algumas Instituições de Ensino Superior (IES) implantam a utilização de metodologias ativas em seus processos didáticos. A partir disso, surge a discussão a respeito da utilização dessas metodologias para estimular os estudantes a se envolverem mais com seu processo de aprendizagem (FINI, 2018). As metodologias ativas buscam preparar o aluno por meio da participação integral às aulas, utilizando experiências reais ou simuladas, visando as condições de solucionar, com sucesso, desafios advindos das atividades essenciais à prática social em diferentes contextos (BERBEL, 2011). Alguns autores, como Matheson e Sutcliffe 
(2017), discutem a relevância do estudante ser preparado para possuir uma visão de futuro, em que desenvolve características essenciais para o convívio em um mundo de constante transformação e que demanda soluções criativas e engajamento com problemas complexos.

A gamificação é uma dessas técnicas que oferecem abordagem ativa, consistindo na utilização de elementos que são comumente encontrados em jogos, como rankings, histórias, competição, pontos e premiação para motivar e engajar os alunos (BUCKLEY \& DOYLE, 2017; FUCHS, 2014; WERBACH \& HUNTER, 2012) a participarem ativamente do processo de ensino-aprendizagem (FREITAS et al., 2016). Na última década, houve crescente interesse a respeito do papel que os jogos desempenham no contexto educacional e para o aprendizado (GEE, 2008; BRAGA; SOUZA, 2016), juntamente com valorização cultural e a intensificação da conscientização sobre seus benefícios quando aplicados em várias situações (DOMINGUES, 2018). Desde o surgimento do conceito por volta de 2010, a gamificação tem cada vez mais chamado a atenção de acadêmicos e profissionais (Koivisto \& Hamari, 2019). Um ponto que merece destaque é que, embora a gamificação tenha se originado devido à popularização dos jogos digitais, sua aplicação não se restringe aos ambientes digitais.

O termo gamificação faz referência à utilização de elementos que compõem jogos em contextos que não são jogos (Deterding, Dixon, Khaled, \& Nacke, 2011), como em aulas e em treinamentos corporativos. Quando aplicada na educação, a gamificação volta-se à utilização dos elementos de jogos para o desenvolvimento acadêmico do aluno, tanto em cenários formais quanto informais (SEABORN; FELS, 2015), como forma de motivar o estudante para o aprendizado (GEE, 2008). A aprendizagem gamificada, em alguns casos, é tida como mais prazerosa quando comparada com a tradicional (Freitas et al., 2016).

O conceito de motivação é utilizado para explicar o grau em que os alunos investem atenção e esforço em diversas atividades e está conectado à sua vontade de se envolver em aulas e atividades, e suas razões para fazê-lo (BROPHY, 2013). A motivação é tida como um dos fatores essenciais para a aprendizagem (Pilelti, 2008), pois orienta o indivíduo a alcançar seus objetivos (TAPIA; FITA, 2015). Os indivíduos podem ser intrínseca ou extrinsecamente motivados. A motivação intrínseca vem do próprio individuo, estando relacionada a fatores afetivos, voltando-se ao prazer e satisfação derivada da participação em alguma tarefa. Já os extrinsecamente motivados costumam apresentar uma série de comportamentos que são influenciados por fatores externos, relacionados ao ambiente, se voltando a mediar seus comportamentos para conseguir cumprir requisitos e obter recompensas que valorizam. 
Como exemplo, um estudante intrinsecamente motivado vai à aula porque acha interessante e satisfatório aprender mais sobre certos assuntos, já um extrinsecamente motivado tem a mesma atitude porque pensa que receberá alguma recompensa se assim o fizer, como conseguir bom emprego no futuro (VALLERAND et al., 1992; BUCKLEY; DOYLE, 2016).

Estudos anteriores concentraram seus esforços em analisar o efeito da gamificação na motivação através da utilização de elementos de jogos em atividades eletrônicas (BUCKLEY; DOYLE, 2016; SAILER et al., 2017) e poucos trabalhos utilizam o contexto não digital como cenário. Além disso, conforme indicam Sailer et al. (2017), a literatura geralmente analisa a gamificação como sendo com conceito uniforme, não considerando que, na prática, há diversas formas de gamificar uma atividade. É possível combinar diferentes elementos de jogos de várias maneiras diferentes, o que torna inapropriado estudar os efeitos motivacionais da gamificação sem considerar o impacto de diversos elementos de jogos dentro de um contexto específico.

Partindo desse cenário e da importância atribuída por Berbel (2011) ao registro das experiências dos discentes com as metodologias ativas e dos seus efeitos junto aos alunos para que se possa ampliar as reflexões e os benefícios pedagógicos, este trabalho possui objetivo duplo: analisar a percepção do estudante quanto à influência da gamificação na sua motivação para participar de atividades acadêmicas e analisar quais elementos de jogos estão mais relacionados a motivação intrínseca e extrínseca. A intervenção de aprendizagem gamificada estudada foi uma Semana Acadêmica, realizada em uma universidade no interior de São Paulo, que foi reformulada especialmente para esse novo contexto educacional com a utilização de elementos de jogos para tentar motivar os estudantes a participarem ativamente das atividades propostas. O evento analisado é tradicional na instituição estudada e como os entrevistados possuíram contato com os eventos anteriores realizados no molde antigo, permite que sejam captadas as percepções dos estudantes no momento de transição da aprendizagem passiva para a ativa.

\section{Elementos de jogos}

Como as IES possuem o papel de preparar os estudantes para que desenvolvam competências capazes de provocar mudanças transformadoras no ambiente no qual estão inseridos (MATHESON; SUTCLIFFE, 2017), a gamificação pode ser uma aliada no processo de ensino-aprendizagem, aumentando a motivação, desempenho e engajamento dos estudantes (BUCKLEY; DOYLE, 2017). 
Em relação à forma como as práticas gamificadas são desenhadas, Werbach e Hunter (2012) indicam que existem três categorias de elementos de jogos que devem ser consideradas: dinâmicas, mecânicas e componentes (Figura 1). Esses elementos são organizados de maneira decrescente quanto ao nível de abstração, de modo que mantenham ligação com os níveis inferiores e superiores. Considerando que há dependência entre cada nível, é necessário que os elementos de níveis inferiores sejam capazes de operacionalizar os níveis superiores.

\section{Figura 1 - Dinâmicas, Mecânicas e Componentes da gamificação}

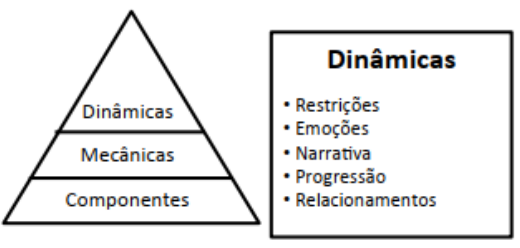

\begin{tabular}{|l|}
\hline \multicolumn{1}{|c|}{ Mecânicas } \\
- Desafios \\
- Sorte \\
- Competição \\
- Cooperação \\
- Retorno \\
- Aquisição de Recursos \\
- Recompensa \\
- Transações \\
- Turnos \\
- Estado de Vitória \\
\end{tabular}

Componentes
- Atingimentos
- Avatar
- Medalhas
- Lutas com chefe
- Coleções
- Combate
- Desbloqueio de
conteúdo
- Presentear
- Quadro de Líderes
- Níveis
- Pontos
- Desafios
- Grafo Social
- Times
- Bens Virtuais

Fonte: Adaptado de Galegale (2014) e Werbach; Hunter (2012)

Assim, como as dinâmicas representam o nível mais alto de abstração e não necessitam estar explicitamente expostas aos indivíduos, é fundamental que as mecânicas e os componentes, respectivamente, sejam escolhidos para que possam concretizar a dinâmica (WERBACH \& HUNTER, 2012). Cada prática gamificada é composta de uma combinação de elementos, não necessariamente todos, mas de modo que os elementos selecionados possam permitir que as mecânicas e as dinâmicas aconteçam (WERBACH \& HUNTER, 2012). Desses três níveis, os componentes são o que estão em contato direto com o usuário.

O estudo realizado por Costa e Marchiori (2015) identificou na literatura as áreas do conhecimento que mais publicavam sobre gamificação e dentro dessas áreas quais elementos de jogos eram mais presentes, seguindo o modelo de Werbach e Hunter (2012). Como resultado, obteve-se que a gamificação é muito utilizada nas áreas de negócios (marketing, treinamento, colaboratividade e produtividade), educação, saúde e esporte. Em relação à 
área da educação, as pesquisadoras identificaram que há a presença de todas as dinâmicas, com destaque para a progressão. No que diz respeito às mecânicas, os mais presentes foram cooperação e competição, desafios e feedback. Por fim, os componentes mais utilizados eram pontos, ranking, conquista e nível.

Conforme indicam Buckley e Doyle (2016), alguns estudantes possuem dificuldades com alguns aspectos da gamificação, pois podem não gostar de algum elemento utilizado, com destaque para a competição e para o fato de não ter somente uma resposta certa para cada objetivo/atividade.

\section{Metodologia}

Como o objetivo deste estudo é analisar a percepção do estudante quanto à influência da gamificação na sua motivação para participar de atividades acadêmicas e analisar quais elementos de jogos estão mais relacionados a motivação intrínseca e extrínseca, considera-se que a abordagem de pesquisa qualitativa é a que melhor se aplica, pois permite entender em maior profundidade a complexidade e interação entre os elementos envolvidos (MARTINS; THEÓPHILO, 2009; MARCONI; LAKATOS, 2011). A estratégia de pesquisa utilizada foi o Estudo de Caso, que segundo Yin (2001) contribui para a compreensão de fenômenos individuais, organizacionais, sociais e políticos. O estudo de caso é muito comum na pesquisa que envolve aspectos educacionais, já que permite analisar o fenômeno de interesse no contexto em que ocorre (CHIZZOTTI, 2006).

Considerando que na pesquisa qualitativa a seleção dos locais e indivíduos que farão parte do estudo é feita intencionalmente para ajudar o pesquisador a atingir seus objetivos (CRESWELL, 2010), as entrevistas foram realizadas com estudantes que participaram das atividades das semanas acadêmicas de anos anteriores e da atual. Como o evento acadêmico foi desenvolvido para os estudantes de todos os semestres dos cursos de Arquitetura e Urbanismo e Publicidade e Propaganda, foram entrevistados 11 alunos de ambos os cursos e de distintos semestres, com exceção do primeiro, pois é importante para o objetivo da pesquisa que os alunos já tenham tido contato com o evento em seu modelo utilizado em anos anteriores, sendo essa a questão filtro.

\section{Estrutura e organização do evento}

Em relação à estrutura do evento, a priori foi realizada uma reunião com os inscritos para divulgar o regulamento da Semana, definir os integrantes 
de cada equipe e explicar sobre a premiação. Ao todo, havia 194 participantes e que foram divididos em grupos de 12 alunos com mistura de estudantes dos cursos de Arquitetura e Urbanismo e Publicidade e Propaganda. A formação desses times foi pensada de modo que houvesse colaboração intragrupo e competição intergrupos. Cada grupo teve um nome escolhido pelos alunos. Com base num tema estabelecido pela comissão, as equipes tinham o desafio de produzir materiais condizentes com os conteúdos que aprendem na faculdade até o fim do evento. Os grupos foram estimulados a ter autonomia e buscar a melhor forma possível para desenvolver os materiais, mas em caso de dúvida, poderiam ser assessorados por docentes.

Os materiais desenvolvidos foram submetidos a um grupo no Facebook no decorrer da semana. As equipes receberam pontos e foram classificadas de acordo com o número de curtidas no material submetido na rede social e pela nota dos docentes. Os estudantes podiam se avaliar por meio da comparação de curtidas em relação às outras equipes. Por fim, foi emitida uma tabela com os resultados e a equipe vencedora foi contemplada com prêmio. Essa edição da Semana Acadêmica trabalhou no âmbito da produção artística estimulada por competição premiada, por outro lado, as edições anteriores forneceram somente oficinas artísticas para a formação extracurricular dos alunos.

O roteiro de entrevista semiestruturada foi desenvolvido considerando a literatura relevante sobre o tema. Ao todo, o roteiro continha inicialmente 10 perguntas que foram feitas a todos os estudantes que participaram do processo de coleta, mas devido à estratégia escolhida, foram feitas mais perguntas de acordo com a resposta obtida, visando maior profundidade nos dados (GIL, 2008). Destaca-se que as entrevistas foram realizadas poucos dias após o término das atividades e o anúncio dos vencedores. Optou-se pela realização das mesmas após o evento, pois assim foi possível conseguir informações tanto de integrantes que venceram, quanto dos que perderam, para não enviesar a amostra. As entrevistas, com tempo médio de 15 minutos, foram gravadas com a autorização dos entrevistados. Posteriormente, os áudios foram transcritos em um processador de textos e foram distribuídos aleatoriamente números entre 1 e 11 para cada indivíduo para que pudessem ser citados neste trabalho sem ferir o anonimato.

\section{Análise de conteúdo}

Após o processamento e edição dos textos, as entrevistas foram ana- 
lisadas seguindo a metodologia da Análise de conteúdo proposta por Bardin (1977). Para facilitar o tratamento, classificação e análise do corpus textual, foi utilizado o software de análise qualitativa Atlas.ti. Seguindo a proposta da autora, após feita a pré-análise dos documentos, foi iniciado o processo de codificação. Nessa etapa, a partir de citações das entrevistas, atribuíram-se códigos aos textos e os foi feita a categorização em grupos de códigos, conforme mostra o Quadro 1:

\section{Quadro 1 - Os códigos elencados para a análise de conteúdo com base no aporte teórico levantado}

\begin{tabular}{|c|c|c|c|}
\hline $\begin{array}{l}\text { Grupos de } \\
\text { Códigos }\end{array}$ & Código & Definições & Autores \\
\hline \multirow{2}{*}{ Motivação } & Intrínseca & $\begin{array}{l}\text { Vontade de aprender, conhecer, } \\
\text { explorar, participar, aperfeiçoar } \\
\text { habilidades, ter estímulos estéticos ou } \\
\text { sensoriais, ou pelo simples prazer e } \\
\text { satisfação em realizar a tarefa }\end{array}$ & \multirow{2}{*}{$\begin{array}{c}\text { Vallerand } \\
\text { et al. } \\
(1992)\end{array}$} \\
\hline & Extrínseca & $\begin{array}{l}\text { Fatores originados do ambiente } \\
\text { externo que influenciam o indivíduo a } \\
\text { cumprir requisitos, metas ou tarefas a } \\
\text { fim obter recompensas, premiações ou } \\
\text { bônus }\end{array}$ & \\
\hline \multirow{7}{*}{$\begin{array}{c}\text { Elementos } \\
\text { de jogos: } \\
\text { Componentes }\end{array}$} & Conquista & $\begin{array}{l}\text { São dados a jogadores que realizam um } \\
\text { conjunto específico de tarefas }\end{array}$ & \multirow{7}{*}{$\begin{array}{c}\text { Werbach } \\
\text { \& Hunter } \\
\text { (2012) }\end{array}$} \\
\hline & Combate & Luta e derrota de um oponente & \\
\hline & $\begin{array}{l}\text { Quadro de } \\
\text { líderes }\end{array}$ & $\begin{array}{l}\text { Lista os jogadores e seus pontos de } \\
\text { forma ordenada }\end{array}$ & \\
\hline & Pontos & Representação do progresso no jogo & \\
\hline & Desafios & $\begin{array}{l}\text { Um conjunto estruturado de ações } \\
\text { esperadas }\end{array}$ & \\
\hline & $\begin{array}{l}\text { Grafo } \\
\text { social }\end{array}$ & $\begin{array}{l}\text { Habilidade de ver o que seus amigos } \\
\text { estão fazendo dentro do jogo }\end{array}$ & \\
\hline & Times & $\begin{array}{l}\text { Possibilidade de trabalhar com outros } \\
\text { jogadores em busca de um ideal }\end{array}$ & \\
\hline
\end{tabular}

Fonte: Elaborado pelos autores (2020). 
O próximo passo foi o tratamento e interpretação dos resultados. Para tal, foi exportado do software a frequência que os códigos apareceram no corpus e a planilha de coocorrência de códigos (quando dois ou mais códigos aparecem em uma mesma citação). Por fim, a interpretação do material gerado foi feita qualitativamente pelos pesquisadores e é apresentada na próxima seção.

\section{Resultados e discussão}

\section{Utilização de metodologias ativas e motivação}

Inicialmente, foi perguntado aos entrevistados como reagiram quando souberam que a Semana Acadêmica fora reformulada e que agora contaria com metodologias ativas, havendo trabalho em equipe, competição, colaboração, pontuações e um prêmio para a equipe vencedora. Por meio da análise das entrevistas, é possível notar a existência de 3 grupos: (a) acharam a mudança positiva, (b) acharam a mudança negativa e (c) foram indiferentes.

Foram 4 alunos que se mostraram animados com a mudança no evento no dia do anúncio, enquanto 6 a viram como um fator desanimador. 0 ocorrido condiz com o esperado, visto que os indivíduos possuem diferenças fundamentais quanto aquilo que os motiva ou não. Além disso, outro fator relevante diz respeito aos estilos de aprendizagem do estudante, pois como relatado por Felder e Silverman (1988), os estudantes apresentam forte tendência e preferência a determinadas dimensões, que definem as formas de receber, processar, perceber e organizar a informação. Destaca-se, neste momento, a fala do entrevistado 5 ao ser questionado o motivo de ter ficado desanimado com a mudança: "porque a gente tinha outra ideia da 'Semana da Arquitetura'. Eles vieram com essa ideia nova e a gente não sabia o que esperar..." (E.5).

Após questionar sobre as impressões iniciais, foi perguntado aos estudantes se durante o evento se sentiram motivados a participar das atividades. Em $82 \%$ dos casos a resposta foi afirmativa. Alguns trechos indicam que a motivação para as atividades foi surgindo a partir de resultados anteriores positivos encontrados pelo grupo do entrevistado: "nos primeiros dias não muito, mas nos outros dias que a gente viu que o trabalho estava ficando legal, aí foi animando mais." (E.7), ou ainda, "Sim, mas não desde o começo... No começo eu achava que seria ruim" (E.1).

Em relação aos casos em que não houve motivação (1), ou ainda, a motivação foi perdida no decorrer do evento (2), os fatores expressados re- 
ferem-se à grande quantidade de atividades e a falta de tempo, que na visão deles prejudicou as entregas ("Um tempo sim, bem no começo assim, mas mais pro final não, porque ficou muita coisa, a gente nem queria entregar quase, ficou muita coisa pro final também"- E. 4) e também sobre a falta de afinidade percebida pelo aluno com os desafios propostos ("Depende... Tinha muita coisa e nem tudo anima a todos a fazer"- E.8). O entrevistado 11 descreve que, em alguns momentos, sentiu-se motivado, mas que devido a não confirmação das suas expectativas a respeito da execução das atividades pelo grupo, não se sentia mais motivado.

Ao serem questionados sobre se sentirem envolvidos com as atividades, oito entrevistados afirmaram que sim. Destaca-se o seguinte trecho de uma das falas:

Sim, porque eu achei que essa divisão dos grupos colocou uma responsabilidade sobre mim e eu tinha consciência dessa responsabilidade, tanto do que eu tinha que aprender, tanto do que eu tinha que demonstrar pro grupo e achei que isso foi interessante, eu gostei. Eu tinha vontade de contribuir tanto pra ter um progresso do grupo como um todo, quanto no desenvolvimento pessoal. A partir do momento que o grupo propõe algo diferente, aprendo com eles e quero levar adiante. Eu tinha vontade de participar. (E.6).

Entretanto, o oposto também ocorreu em três casos. Eles afirmaram que não se sentiram muito envolvidos com os desafios propostos, não contribuindo de maneira voluntária com o grupo e ficaram "recebendo ordens e esperando o tempo passar" (E.9), como disse um dos estudantes. Além disso, outro estudante (E.8) relatou estar participando do evento somente porque haveria o ganho de horas extracurriculares. Nesse ponto, destaca-se a importância de se analisar mais profundamente os motivos que levam esses alunos a não se envolverem com as atividades e contribuírem ativamente para o grupo, uma vez que isso pode atrapalhar seu processo de aprendizagem. Morán (2015) entende que para o sucesso da aprendizagem, não basta que as atividades ou desafios sejam desenvolvidos considerando as competências necessárias para cada etapa educacional, mas também deve haver a combinação de recursos educacionais ou metodologias que envolvam participação significativa em grupos.

As metodologias ativas de ensino-aprendizagem valorizam muito o trabalho em grupo, de modo que as experiências e conhecimentos individuais dos estudantes possam contribuir para a formação do grupo como um todo. 
Em várias técnicas de metodologias ativas, como em Estudos de Caso, ou Aprendizado Baseado em Problemas, a atividade grupal desempenha papel importante na construção do conhecimento. Devido à relevância do grupo, os estudantes foram questionados a respeito da experiência de trabalhar com grupos, principalmente devido à tentativa da equipe organizadora do evento de mesclar alunos de turmas e cursos distintos. O Quadro 2 sistematiza as falas dos estudantes que acharam a experiência positiva.

Quadro 2 - Como foi a experiência de trabalhar em equipes formadas de alunos de cursos, semestres, competências e personalidades diferentes?

\begin{tabular}{|c|l|}
\hline Ent. & \multicolumn{1}{|c|}{ Resposta } \\
\hline $\mathbf{3}$ & $\begin{array}{l}\text { "Foi legal, diversidade de alunos, interessante. A gente conhecia as } \\
\text { pessoasmelhor, tercursos diferentes ajudou a terideias diferentes..." }\end{array}$ \\
\hline $\mathbf{5}$ & $\begin{array}{l}\text { "Sim foi bom porque trocou experiências, conhecimentos, ajudou } \\
\text { bastante isso aí... até tipo, cada um tem um gosto né, então isso } \\
\text { diferenciou um pouco né, essa diferença acabou contribuindo pro } \\
\text { trabalho em si do grupo" }\end{array}$ \\
\hline $\mathbf{6}$ & $\begin{array}{l}\text { "Foi muito bom para vermos o mundo de outras perspectivas, não } \\
\text { só da arquitetura." } \\
\text { "Acho que ajudou bastante, acho que com essas competências } \\
\text { teve uma troca boa de informações e tanto eles entenderam que } \\
\text { nós não tínhamos tanto essa competência, quanto nós sabíamos } \\
\text { interessante. Não sei se pra eles que tinham [competências] a } \\
\text { mais foi tão interessante, mas pra gente que sabia menos, foi } \\
\text { interessante. Nós dividimos as tarefas, mas dentro do que cada um } \\
\text { recebeu trabalhamos em equipe muito bem." }\end{array}$ \\
\hline
\end{tabular}




\begin{tabular}{|c|l|}
\hline 9 & $\begin{array}{l}\text { "Não tive dificuldades, até porque eu tinha amizade com todos, } \\
\text { menos um do grupo. Mas alguns dos meus amigos estavam num } \\
\text { grupo em que não se conheciam, então não sei comofoi a experencia } \\
\text { deles, mas a minha foi bacana. Sobre o pessoal de PP [Publicidade } \\
\text { e Propaganda], dois meninos ajudaram bastante no logo e outro } \\
\text { ajudou bastante nas ideias. Eles ficavam um pouco distantes as } \\
\text { vezes, mas quando eles ficavam com a gente, eles se integravam } \\
\text { bem com a gente, menos esse que mencionei que não conhecia que } \\
\text { ele ficou ali, meio avoado, distante. Trabalhamos bem, mas ficou } \\
\text { um pouco dividido em pequenos grupos." }\end{array}$ \\
\hline 10 & $\begin{array}{l}\text { "Achei que foi muito bom, porque consegui muita experiencia, o } \\
\text { pessoal do 40 ano que tava fazendo projeto com a gente, eles deram } \\
\text { várias dicas pra gente, a gente aprendeu muita coisa de [Auto]CAD } \\
\text { que a gente não sabia e que acabamos não aprendendo aqui, fora } \\
\text { ojeito das outras pessoas pensarem, você acaba aprendendo muito } \\
\text { com isso. Acho que trabalhamos uns 90\% em equipe." }\end{array}$ \\
\hline
\end{tabular}

Fonte: Elaborado pelos autores (2019).

Por meio da análise das respostas que identificaram a experiência como positiva, algumas considerações surgem: alguns alunos valorizam a troca de informações e conhecimentos ao trabalhar em equipes, tendo a percepção que a combinação de diferentes gostos e personalidades contribuiu na totalidade; alguns estudantes entendem que aprenderam ao trabalhar com indivíduos que se encontram em semestres posteriores (ex. E.10). Isso também se torna evidente na fala do entrevistado 6 sobre o evento e sua percepção sobre sua aprendizagem comparada com a de alunos veteranos: "Não sei se pra eles que tinham [competências] a mais foi tão interessante, mas pra gente que sabia menos, foi interessante...". Por meio dessa visão, fica evidente a motivação intrínseca presente em alguns participantes, ou seja, os participantes estavam motivados pelo ganho intelectual e autorrealização trazida pelos grupos.

Entretanto, não foram todos os alunos que viram a divisão em grupos de forma positiva. O entrevistado 11 contou que, em seu grupo, a maior parte dos alunos estava em época de terminar o Trabalho de Conclusão de Curso (TCC), então não se dedicaram aos desafios propostos no evento:

[Os outros integrantes do grupo] são gente boa, são bacanas. Se não fosse o TCC teria sido bem melhor, mas todo momento eles diziam que era o TCC, que era a maior 
urgência e que o evento tava sendo feito mesmo só pras horas extracurriculares. (E.11).

O mesmo aluno também comentou que não houve troca de conhecimento e que não conseguiu aprender com os colegas de equipe, pois não estavam todos envolvidos: "dois estavam envolvidos, os demais não, sempre a desculpa era o TCC." Esse tipo de situação ocorreu, pois, os próprios participantes formaram seus grupos, sendo assim, foi comum encontrar grupos com vários alunos do mesmo curso e semestre. Dessa forma, havia grupos com grandes quantidades de alunos em ano de conclusão de curso, bem como grupos com vários alunos ingressantes desorientados quanto às atividades propostas. Elementos de jogos e motivação

Este tópico se dedica às questões que estão mais diretamente relacionadas a utilização de elementos de jogos e a motivação do estudante. Considera-se que não existam elementos que são exclusivamente dos jogos (WERBACH \& HUNTER, 2012), mas alguns elementos são mais utilizados que outros, principalmente em estratégias de gamificação voltadas à educação. Portanto, para esta análise, foram utilizados os elementos de jogos elencados por Werbach \& Hunter (2012) e que estiveram presentes no evento: conquista, combate, quadro de líderes, pontos, desafios, grafo social e times.

Dessa forma, para identificar a percepção dos estudantes sobre a utilização de elementos de jogos, foi realizada a seguinte questão: “Você acha que ter utilizado uma competição, com premiação, a utilização de pontuações para cada desafio alcançado e a divulgação em forma de rankings, te motivaram a participar das atividades?". As respostas afirmativas corresponderam a $82 \%$ do total. Ao serem questionados a respeito do que mais motivava, se era a competição ou a existência de uma premiação no final, os estudantes dividiram-se entre aqueles que afirmavam ser o prêmio, a competição, ou ainda, que foram os dois (Quadro 3).

Quadro 3 - O que mais te motivava: a competição entre as equipes ou a premiação no final?

\begin{tabular}{|c|c|}
\hline Ent. & Resposta \\
\hline 1 & "No início foi a competição, mas no meio, o prêmio" \\
\hline
\end{tabular}




\begin{tabular}{|c|c|}
\hline 2 & $\begin{array}{l}\text { "Eu acho que motivou mais entregar...claro que você também } \\
\text { tá focado né, mas no objetivo de entregar tudo, de completar as } \\
\text { etapas." }\end{array}$ \\
\hline 3 & "A premiação mais." \\
\hline 4 & "Tentar fazer melhor, destacar o grupo." \\
\hline 5 & $\begin{array}{l}\text { "Acho que as horas extracurriculares... Porque a gente entra e não } \\
\text { pensa que vai ganhar." }\end{array}$ \\
\hline 6 & $\begin{array}{l}\text { "Ah, um pouco de cada. Tanto queríamos mostrar o que a gente } \\
\text { tinha feito e sabíamos fazer, tanto dentro quanto fora do grupo, } \\
\text { quanto esperávamos a premiação. Então foi um pouco de cada. } \\
\text { A vontade de aprender e a vontade de ganhar serviram uma de } \\
\text { apoio pra outra." }\end{array}$ \\
\hline 7 & $\begin{array}{l}\text { "Acho que mais a parte da disputa, o prêmio eu não tava muito } \\
\text { ligando." }\end{array}$ \\
\hline 8 & "Não o prêmio em si, só mais a competição e mostrar o trabalho." \\
\hline 9 & $\begin{array}{l}\text { "Ah não sei, eu queria fazer, queria mostrar que tinha competência } \\
\text { e conseguia fazer. Foi um desafio, uma semana pra fazer tudo, foi } \\
\text { bem bacana e conseguimos ver que a gente podia fazer e dava pra } \\
\text { fazer, então o pessoal dava ideia." }\end{array}$ \\
\hline 10 & $\begin{array}{l}\text { "Acho que nenhum dos dois, acho que pra mim [...], no começo } \\
\text { cheguei sem um objetivo, mas no meio [da semana] o que me } \\
\text { motivou era eu estar aprendendo ali, pra mim acho que foi isso, } \\
\text { nem tava pensando em ganhar de alguém, ou ganhar a viagem." }\end{array}$ \\
\hline 11 & $\begin{array}{l}\text { "Sinceramente, nenhuma das duas. O que me motivou foi ver que } \\
\text { o evento melhorou em comparação com o ano passado, que no } \\
\text { meu ponto de vista foi um desastre. Esse ano acho que teve uma } \\
\text { interação maior dos alunos, teve a competição que achei que foi } \\
\text { algo saudável, houve a competição... mas foi bem melhor que o } \\
\text { ano passado." }\end{array}$ \\
\hline
\end{tabular}

Fonte: Elaborado pelos autores (2019).

Com base nas respostas, é possível identificar que a pluralidade de elementos de jogos é bem-vinda em estratégias gamificadas, pois os indivíduos possuem preferências distintas e se motivam extrinsecamente por diversos fatores. Além disso, é importante dar destaque à fala dos entrevistados $6 \mathrm{e}$ 
10, pois, a motivação extrínseca proporcionada pela utilização de elementos de jogos foi importante, para os dois no começo das atividades, mas posteriormente a vontade de ganhar a competição ou o prêmio foram substituídas pelo desejo de aprender. Isso indica que, embora Berbel (2011) entenda que a motivação extrínseca pode diminuir as possibilidades de manifesto das motivações intrínsecas, alguns alunos sentiram-se de fato engajados nas atividades, utilizando-as para aprender.

A motivação ainda foi objeto de interesse de mais uma pergunta feita pelo entrevistador: "em sua opinião, o prazo estabelecido pela comissão para a entrega dos resultados funcionou como uma motivação que auxiliou na organização das tarefas, ou como uma barreira criativa e algo preocupante durante a elaboração dos itens?". Do total, nove entrevistados consideram que ter limite de tempo é algo positivo, enquanto dois consideram como barreira. Daqueles do primeiro grupo, destaca-se o comentário do Entrevistado 6, que considera o prazo como motivador, porém considera que os prazos estabelecidos para os desafios foram curtos de mais:

O prazo motivou a gente a entregar um bom trabalho, mas ao mesmo tempo funcionou como uma barreira de comunicação. Por exemplo, o pessoal que entendia mais de 3D, nós não conseguimos conversar com eles de como é feito um 3D, a gente simplesmente falou 'olha, como vocês sabem fazer e nós temos que entregar rápido, vocês fazem'. Então acho que o tempo poderia ter sido maior ou ter tido mais tarefas, pra ter mais essa comunicação. Mas acho que o tempo não foi algo que bloqueou o grupo e fez a gente não entregar nada. (E.6).

Para complementar a análise dos resultados, é essencial trazer uma perspectiva quantitativa da codificação executada. O Quadro 4 quantifica a frequência que os códigos relacionados a elementos de jogos aparecem no corpus textual: 
Quadro 4 - Quantificação da frequência em que os códigos aparecem nas falas registradas.

\begin{tabular}{|c|c|c|}
\hline Grupos de Códigos & Código & Frequência \\
\hline \multirow{4}{*}{$\begin{array}{c}\text { Elementos de jogos: } \\
\text { Componentes }\end{array}$} & Times & 31 \\
\cline { 2 - 3 } & Combate & 15 \\
\cline { 2 - 3 } & Conquista & 14 \\
\cline { 2 - 3 } & Desafios & 11 \\
\cline { 2 - 3 } & Grafo social & 6 \\
\cline { 2 - 3 } & Pontos & 4 \\
\cline { 2 - 3 } & Quadro de líderes & 2 \\
\hline
\end{tabular}

Fonte: Elaborado pelos autores (2020).

O código "Times" é o mais frequente, ou seja, a questão do trabalho em grupo foi citada mais vezes durante a pesquisa. Em sequência, o código "Combate" - referente às disputas entre grupos - é apresentado. A partir disso, é possível fazer uma conexão entre tais códigos: provavelmente o cerne motivacional do evento estava presente nos grupos, englobando questões intrínsecas (aprendizado e participação) e extrínsecas (presença de outros grupos e a competição). Por fim, código "Conquista" também foi um dos mais frequentes - o que pode evidenciar a importância da premiação final como um motivador externo que permanece durante todo evento.

Já ao analisar qual tipo de motivação esteve mais presente na Semana Acadêmica, o código referente à motivação extrínseca desponta com 48 marcações. Por outro lado, a motivação intrínseca apareceu no corpus 17 vezes. Portanto, frases relacionadas à motivação extrínseca (referindo-se ao prêmio, competição, prazos, metas, etc.) foram mais evidentes nas falas dos participantes.

Por fim, foi realizada uma análise de coocorrência de códigos para elencar quais elementos de jogos estão mais conectados aos diferentes tipos de motivação. A motivação intrínseca esteve mais relacionada com o código "Times" (12 coocorrências), o que pode se referir à aquela questão do aprendizado intragrupos e autorrealização por participação grupal (Figura 2). 
Figura 2 - Quais elementos de jogos coocorrem com a motivação intrínseca e extrínseca

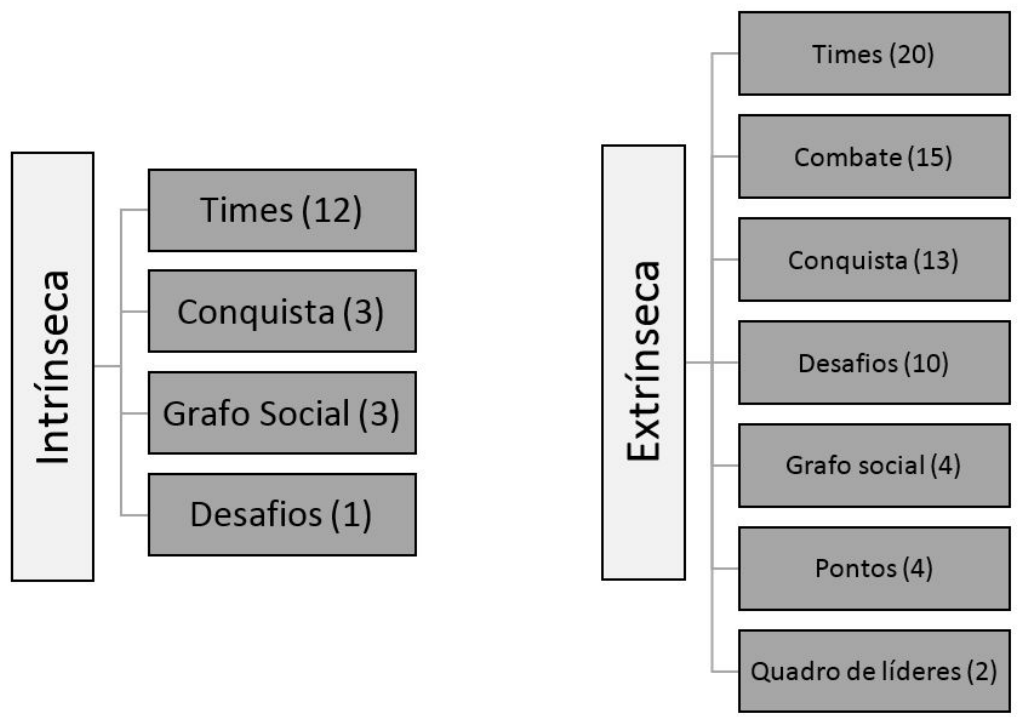

Fonte: Elaborado pelos autores (2020).

A motivação extrínseca também se relacionou mais com o código "Times" (20 coocorrências), o que pode remeter às falas de quando o grupo e seus participantes influenciaram o entrevistado a contribuir (Figura 2). Já ao quantificar o total de coocorrências fica destacado que, no evento em estudo, a motivação extrínseca se relacionou mais com os elementos de jogos do que a intrínseca: 68 coocorrências para a primeira e 19 para a segunda.

\section{Considerações finais}

O principal objetivo deste artigo consistiu em analisar a percepção do estudante quanto a influência da gamificação na sua motivação para participar de atividades acadêmicas e analisar quais elementos de jogos estão mais relacionados a motivação intrínseca e extrínseca. Dessa forma, como se pôde avaliar, a transformação para abordagem metodológica mais ativa e gamificada do evento teve influência na motivação dos estudantes. Os elementos de jogos tiveram boa recepção por parte dos alunos, uma vez que $82 \%$ dos entrevistados responderam positivamente à motivação extrínseca feita por tais elementos. Foi possível identificar que nem todos os estudantes responderam 
da mesma forma aos estímulos, conforme já era previsto. Também foi possível identificar, através da análise de conteúdo, que determinados elementos estão mais relacionados a motivação extrínseca, enquanto outros influenciam mais os alunos intrinsecamente motivados.

Uma das limitações desta pesquisa volta-se à quantidade de entrevistas realizadas. Além disso, também seria interessante acompanhar outras semanas acadêmicas de outros cursos. Espera-se que os resultados possam contribuir de maneira prática, pois podem servir para auxiliar na concepção ou melhoria de eventos acadêmicos que propõem o uso de elementos da gamificação. Dessa forma, para pesquisas futuras, seria relevante oferecer uma visão quantitativa, por meio da prática experimental ou quase-experimental, a respeito da relação entre gamificação e motivação.

\section{Referências}

AMABILE, T. M. et al. The Work Preference Inventory: Assessing intrinsic and extrinsic motivational orientations. Journal of Personality \& Social Psychology, v. 66, n. 5, p. 950-967, 1994.

BARDIN, L. Análise de conteúdo. Lisboa: Edições 70, 1977.

BERBEL, N. A. N. As metodologias ativas e a promoção da autonomia de estudantes. Semina: Ciências Sociais e Humanas, v. 32, n. 1, p. 25, 2011.

BRAGA, J. de C. F.; SOUZA, V. V. S. de. As condições necessárias para a emergência complexa em jogos: um estudo sobre oportunidades de aprendizagem nessas práticas sociais. ReVEL, v. 14, n. 27, p. 304-330, 2016.

BROPHY, J. Motivating students to learn. 2. ed. Routledge, 2013.

BUCKLEY, P.; DOYLE, E. Gamification and student motivation. Interactive Learning Environments, v. 24, n. 6, p. 1162-1175, 2016.

BUCKLEY, P.; DOYLE, E. Individualising gamification: An investigation of the impact of learning styles and personality traits on the efficacy of gamification using a prediction market. Computers \& Education, v. 106, p. 43-55, 2017.

CHIZZOTTI, A. Pesquisa qualitativa em ciências humanas e sociais. Petrópolis: Vozes, 2006.

COSTA, A. C. S.; MARCHIORI, P. Z. Gamificação, elementos de jogos e estratégia: uma matriz de referência. Revista de Ciência da Informação e Documen- 
tação, v. 6, n. 2, p. 44, 2 out. 2015. Disponível em: http://www.revistas.usp. br/incid/article/view/89912

CRESWELL, J. W. Projeto de pesquisa: Métodos qualitativo, quantitativo e misto. 3. ed. Porto Alegre: Artmed, 2010.

DETERDING, S.; DIXON, D. Gamification: Using Game Design Elements in Non-Gaming Contexts. In: Proceedings of the International Conference on Human Factors in Computing Systems. 2011.

DOMINGUES, D. O sentido da gamificação. In: Gamificação em debate. São Paulo: Blucher, 2018. p. 212.

FELDER, R. M.; SILVERMAN, L. K. Learning and teaching styles in engineering education. Engineering education, v. 78, n. 7, p. 674-681, 1988.

FINI, M. I. Inovações no ensino superior: Metodologias inovadoras de aprendizagem e suas relações com o mundo do trabalho: desafios para a transformação de uma cultura. Administração: Ensino e Pesquisa, v. 19, n. 1, p. 176-183, 2018.

FREITAS, S. A. A. et al. Gamificação e avaliação do engajamento dos estudantes em uma disciplina técnica de curso de graduação. In: Brazilian Symposium on Computers in Education. 370-379, 2016.

FUCHS, M. Gamification as twenty-first-century ideology. Journal of Gaming \& Virtual Worlds, v. 6, n. 2, p. 143-157, 2014.

GALEGALE, G. P. A utilização de gamification em um sistema de informação: estudo de caso na Natura Cosméticos S.A. 2014. Universidade de São Paulo, 2014.

GEE, J. P. Learning and Games - The ecology of games: Connecting youth, games, and learning, v. 3, p. 21-40, 2008.

GIL, A. C. Métodos e técnicas de pesquisa social. 6. ed. Editora Atlas SA, 2008.

KOIVISTO, J.; HAMARI, J. Management The rise of motivational information systems: A review of gamification. International Journal of Information Management, v. 45, n. July 2018, p. 191-210, 2019.

MARCONI, M. de A.; LAKATOS, E. M. Metodologia Científica. 6. ed. São Paulo: Editora Atlas S.A., 2011.

MARTINS, G. de A.; THEÓPHILO, C. R. Metodologia da Investigação Científica 
para as Ciências Sociais Aplicadas. 2. ed. São Paulo: Editora Atlas S.A., 2009.

MATHESON, R.; SUTCLIFFE, M. Creating belonging and transformation through the adoption of flexible pedagogies in masters level international business management students. Teaching in Higher Education, v. 22, n. 1, p. 15-29, 2017.

MORÁN, J. Mudando a educação com metodologias ativas. Coleção Mídias Contemporâneas: Convergências Midiáticas, Educação e Cidadania: aproximações jovens, v. 2, p. 15-33, 2015.

NÉRICI, I. G. Didática: Uma introdução. São Paulo: Atlas, 1986.

PILELTI, N. Psicologia Educacional. 17. ed. São Paulo: Editora Ática, 2008.

SAILER, M. et al. How gamification motivates: An experimental study of the effects of specific game design elements on psychological need satisfaction. Computers in Human Behavior, v. 69, p. 371-380, 2017. Disponível em: http:// dx.doi.org/10.1016/j.chb.2016.12.033.

SEABORN, K.; FELS, D. I. Gamification in theory and action: a survey. International Journal of Human Computer Studies, v. 74, p. 14-31, 2015.

TAPIA, J. A.; FITA, E. C. A motivação em sala de aula. São Paulo: Edições Loyola, 2015.

WERBACH, D.; HUNTER, K. For the Win: How Game Thinking Can Revolutionize Your Business. Wharton Digital Press, 2012.

VALLERAND, R. J. et al. The Academic Motivation Scale: A Measure of Intrinsic, Extrinsic, and Amotivation in Education. Educational and Psychological Measurement, v. 52, n. 4, p. 1003-1017, 1992.

YIN, Robert K. Estudo de Caso: Planejamento e métodos. Bookman Editora, 2015. 